\title{
An Evaluation Based on Teachers' and Students' Opinions on Art Curricula in Northern and Southern Cyprus
}

\author{
Fatma Miralay \\ Near East University, Department of Educational Programs and Instruction, Nicosia, Mersin 10, TURKEY
}

Received 25 May 2017 • Revised 10 August 2017 • Accepted 16 September 2017

\begin{abstract}
The purpose of this study is to make an evaluation based on opinions of teachers and students on the Year 8 visual art curricula implemented at the secondary education level in both northern and southern Cyprus schools. Ten Year 8 Visual Art teachers from Northern Cyprus $(n=10)$ and Southern Cyprus $(n=13)$, and 1200 students from both sides participated in this research. Opinions of teachers on the visual art curricula gathered through semi-structured interview forms whereas opinions of students gathered through the "Visual Art Curriculum Evaluation Scale". The findings of research reveal that the value given to the visual art curricula in both communities is low in terms of communal, administrative, managerial and senior managerial perspectives. Furthermore, the findings indicate that compared to Southern Cyprus, there is a further need of financial support, an update and development of the content of visual art curriculum implemented in Northern Cyprus.
\end{abstract}

Keywords: art education, comparative education, Cyprus, program evaluation

\section{INTRODUCTION}

The 21st century also called the technology era, brings constant and rapid developments, causing a change in communities and triggering the quest to make improvements especially in the education systems. During the process of this change, individuals are directly affected by the requirements of the era in relation to social and cultural dynamics, requiring the individual to question, search and display a contemporary profile. In this regard, individuals in need of competencies, which nurture their intellectual capacity, are provided with their needs through quality education. In order to provide the expected competencies, social development, cultural and artistic gains, there is a need for a well-planned educational program (Matthews at al., 2016; Savery, 2015).

An educational program in its broadest terms involves courses and the planning of these courses for the purpose of achieving the targeted goals in individuals. Configuring the educational programs for improvement and enhancing a structure that enables the program to keep up to date are significant necessities of today (Phillips, 2015). Renewing by configuring programs meets the educational needs of individuals and at the same time, suffices future goals of communities (Altbach, 2015; Savery, 2015). Moreover, in addition to the acquisitions of individuals, educational programs also hold a significant effect on countries, communal and cultural functions (Chin, 2016; Karapati et al., 2016). According to specialists, national and cultural identity formation of communities and their relative needs are facilitated through the cultural dimension of education (Hung \&Smith, 2015). Culture in education refers to experiences, which initiate from an individual's own national culture, expanding to an international culture dimension.

(C) Authors. Terms and conditions of Creative Commons Attribution 4.0 International (CC BY 4.0) apply. Correspondence: Fatma Miralay, Near East University, Department of Educational Programs and Instruction, Near East Boulevard, 99138, Nicosia, Mersin 10, Turkey. 


\section{Contribution of this paper to the literature}

- It is believed that this study will shed light on bi-communally conducted scientific research.

- It is the first scientific research on arts education at secondary education level in Northern and Southern Cypriot communities and it is believed that this study will be a reference to similar studies in other arts fields.

- It is believed that this study will contribute to the peace process which is in progress in the island of Cyprus, and will bring in a different insight and contribute to the studies of the civil society, politics and cultural studies, as well as having a positive impact on the environment of bi-communally conducted scientific research.

Learning the culture and raising intercultural awareness are gains, which are only acquired through courses, which include a cultural aspect. In this regard, Dewey (2008), emphasises the role of education in extending both local and national cultural aspects in individuals and points out the direct relationship with contemporary art in education programs. Furthermore, the significance of art as an aspect of culture, and art in education are also emphasised as these lead to the acquisition of skills in extensive areas and enable the transmission of information among different cultures. The presence of art in education is a building block of contemporary education as it nurtures practical skills and intellectual needs of learners

Art education is included in educational programs developed in various different disciplines (Kroflic, 2007) and it adopts a goal which targets to develop artistic skills in individuals. Furthermore, art education aims to develop mutual empathy between individuals and equip them with problem-solving, intellectual thinking, courage, and entrepreneurship skills; especially via visual art education. The new tendencies related to visual art courses emphasise the need to multi-dimensionally learn art, alongside the need to develop aesthetic skills in individuals; visual art courses also play a role in the progress of socialisation (Winkler \& Denmead, 2016). Cremin (2016), refers to Johan Galtung's view on art education, "stating that visual art are a means of developing empathy between individuals and equipping them with social skills; such as finding creative, constructive and peaceful solutions to conflicts". The literature on visual art curricula also points to the significant role which visual art play in facilitating aesthetic gains and creating a common language in European countries (Kraehe et al., 2015). Furthermore, Jeong (2017), also emphasises that visual art courses had the potential to remove the borders between communities, joining them economically and culturally by creating awareness on universal values, without tampering national and local values.

As can be inferred from the available definitions, visual art curricula have a direct impact on equipping individuals with skills which enables them to take communal art to universal values, and with analytical skills to approach issues in their environment. Bringing a different perspective to the subject, Bamford (2006), states that in terms of the relationship between international education systems and visual art curricula, the validity and up-todatedness of educational programs can be maintained via reforms in education. Over and above, Leigh (2015), stresses that, just as it is the case with curricula of all subjects, it was necessary to make evaluations of visual art curricula by making comparisons between different countries so as to improve their effectiveness. Moreover, Sullivan and Margo (2006), take a different approach to the matter of comparative education and express that the education systems of different countries could be holistically or partially compared, which could then help to identify common and or differing aspects. On the other hand, Leeman and Reid (2007), describes the comparative approach in art education as a scientific discipline in terms of theory and application; education policy; education reforms; moderation in international relation and ensuring a peaceful environment. In conclusion, it could be stated that making a comparison of the curricula of different communities while considering the mission and vision of visual art curricula provides the opportunity to ease the relationships between communities, and make comparisons between the differences and similarities among them, which in return enables communities to construct new judgements (Turner, 2016). The two different communities living in Cyprus separated as Northern and Southern Cyprus, use different curriculums and once considering what has stated above, making a comparison of the two communities is seen beneficial for the two communities. In fact, the solution continuum for the Cyprus 
issue, which has been ongoing for 42 years, and the current socio-political status, studies carried out in both communities is seen rather important; especially a comparison of the curriculums of visual artin both the communities. The 42-year continuum has created two distinct education systems independent from each other, one for the Turkish Republic of Northern Cyprus and another for Republic of Cyprus, (Zembylas et al., 2010). In 1960, the education systems of Northern and Southern Cyprus were managed by a joint commission. This later ended when the Turkish community withdrew in 1965 (Kambouri, 2008; Papadakis, 2008). Greek Cypriot community took the Greek education system as their model and from the date they entered the European Union in 2004, shifted their education system to a global platform, improving the cultural dimension of education (Zembylas, 2002).

On the other hand, since 1965 the Turkish Cypriot community took the education system of Republic of Turkey as a model (Gökel \& Dağlı 2015). The literature review reveals that there has been a high interest in conducting research on bi-communal communities in terms of comparative education. However, comparative studies conducted in Cyprus were politically oriented; rather than involving factual values, they involved subjective notions directed to Cyprus History educational programs (Zembylas \& Charalambous \& Charalambous, 2016). On the other hand, Kizilyürek (2016), emphasises the significance of activities involving art in education in schools of both Greek and Turkish Cypriots. He further adds that education required reconstruction to integrate the above-mentioned concepts; which then causes the individuals, which share the same country, to get to know each other as they sought for a joint future while getting rid of their prejudices. In this regard, the mission of art and visual art courses is seen rather significant as they lead to a universal language, binding communities and forming objective expressions; and with such significance conducting a study which focuses on a comparative evaluation of visual art curriculums is similarly important. The literature review also points out that a study on the comparative evaluation of the visual art curricula across the island has not been previously conducted. Thus, this particular study is expected to make a contribution to the field. It is also believed that through this research, educators, artists and students will find the opportunity to make a bi-communal evaluation. In this regard, the purpose of this study is to make an evaluation based on the year eight teachers' and students' opinions on visual art curricula implemented in Northern and Southern Cyprus. Therefore, this research sought the answers to the following questions:

(1) What are the opinions of teachers working in Northern and Southern Cyprus on visual art curriculums implemented in year eight, secondary education?

(2) What are the views of year eight teachers, working in Northern and Southern Cyprus, regarding the physical environment where visual art curriculums are applied?

(3) What are the opinions of year eight students, studying in Northern and Southern Cyprus, on visual art curriculums applied in secondary education?

(4) Do taking private lessons for visual art have an influence on year eight students' views regarding the visual art curricula implemented in secondary education in both Northern and Southern Cyprus?

\section{METHODOLOGY}

The purpose of this research was to make an evaluation based on teachers' and students' opinions on year eight visual art curriculum currently implemented both in Northern and Southern Cyprus. For this purpose, a mixed methods approach was utilised and the data for the study was collected via two different methods. Political difficulties on the island were considered and therefore a "convenience sample" was used as the sampling method.

\section{Participants}

The participants of this study selected from teachers working under the body of Ministries of Education of both Turkish Republic of Northern Cyprus and Republic of Cyprus. The participants were a total of 23 teachers $(71.9 \%)$, teaching visual art to year 8 students, and a total of their 1200 students (36.5\%). That is, 10 visual art teachers from Northern Cyprus (100\%) and their 600 (63.8\%) students; and 13 visual art teachers from Southern Cyprus $(59.1 \%)$ and their $600(25.5 \%)$ students participated in the research. 15 of the 23 teacher participants were female $(52.2 \%)$ and 8 were male teachers $(34.8 \%)$. Furthermore, 5 of the participating teachers $(21.7 \%)$ aged between 31 and 
45, 15 of the teachers aged between 36 and $40(65.2 \%)$ and 3 aged between 41 and 45 (13\%). Moreover, 1 of the teachers had a postgraduate degree $(\mathrm{PhD})(4.3 \%), 12$ had a master's degree and 10 had a graduate degree $(43.5 \%)$. Additionally, the teacher participants from Northern Cyprus had different years of experience; such that 1 (10\%) had 5 years of experience; 2 had (20\%) experience ranging between 11-15 years; 4 had (40\%) 16-20 years of experience; and 3 teachers (30\%) of 21 and above years of experience. On the other hand, 2 of the teachers working in Southern Cyprus (15.5\%) had an experience of 5 years; 4 (30.8\%) had experience ranging between 6-10 years; 5 (38.5\%) of which had 21 years and above experience.

While the teachers in Northern Cyprus had previously attended 1-2 in-service training programs, the teachers in Southern Cyprus had attended 5 and above in-service programs. Once the teachers' background on participating in exhibitions was investigated, it was found that the Turkish teachers had participated in 1-2 exhibitions; whereas the Greek teachers had participated in exhibitions 5 or above each year.

\section{Data Collection Instruments}

As the purpose of this study was to make an evaluation based on the year eight teachers' and students' opinions on the visual art curricula and for this purpose, the data collection instruments were developed by in line with the scope of this study. In order to identify the students' opinions, a "Visual Art Curriculum Evaluation Scale" was developed; whereas to identify the teachers' opinions, an interview form for "Visual Art Teachers' opinions on Visual Art Curriculum" was developed. Details regarding the data collection instruments can be found below.

\section{Visual Art Curriculum Evaluation Scale}

In order to collect the quantitative data to identify the opinions of year eight students on the visual art curriculum implemented, a data collection instrument titled as "Visual Art Curriculum Scale" was developed. This scale was developed by the researchers of the study based on Stufflebeam CIPP evaluation model, which requires the evaluation of context, input, process and product. Furthermore, there are two main aspects of this data collection instrument; first of which include demographic features of the participants; and second which focuses on students' opinions on the process and product of the curriculum. The aforementioned demographic features include gender; nationality; parent income status; number of a siblings; status of family members involved in art; whether private lessons are taken on visual art; participation in an art exhibition; and feelings for the visual art course. While developing the Visual Art Curriculum Evaluation Scale, the following three stages were followed;

The first stage is based on the literature review, the second was the establishment of the item pool and the third focused on the evaluation of specialists' views. After the first stage was completed, it was moved on to the second stage. While the item pool was being made it was assured that there was not a loss in meaning and therefore; 2 Turkish and 2 Greek Cypriot teachers were consulted. Subsequent to this stage, the scale items were consulted to 1 program development, 2 assessment and evaluation and 2 visual art education specialists and 5 academicians. The necessary changes were made according to their feedback and the scale was completed as a final draft form with 42 items. Since the pilot of the prepared draft form was going to be implemented in both communities, it was written in two languages; the form to be implemented in southern Cyprus was written in Greek, whereas the form to be implemented in Northern Cyprus was written in Turkish. During the first phase of translated into form to Greek to be used in southern Cyprus, the expressions which were written in Turkish was translated to Greek and then translated back to Turkish. Finally, to check the meaning similarities and differences of the two they were tested on 8 samples.

The pilot questionnaire was administered to Year Eight students $(n=800)$ in 4 different secondary schools in Northern and Southern Nicosia. In order to test the validity of the draft scale, a factor analysis was realised, and the Kaiser-Meyer-Olkin (KMO) value was calculated as 0.954 . The attained value revealed that the scale was valid. Moreover, the reliability factor was identified as Cronbach's Alpha 0.91. This indicated that the scale was reliable. The data collected from the pilot study was also analysed through Exploratory Factor Analysis and Confirmatory Factor Analysis. Considering the Exploratory Factor Analysis, Principal components analysis and varimax rotation were calculated, and from the 42 item draft form, 16 items were removed since their factor load value was found 
to be below 0.50. Moreover, in two factors of the scale, factor I and factor II, a total of 26 items were identified. Furthermore, it was identified that Factor I was $27.03 \%$ of the total variance and Factor II was $17.60 \%$ of the total variance; two-factored structure total variance was $44.62 \%$. Literature shows that the expressed variances changed between 40-60 \% (Arkün \& Asskar 2010). The two factors expressed in this research are over 40\% and therefore shows that it is an acceptable percentage. The two dimensions identified as a result of the factor analysis were named as "continuum dimension of visual art curriculum" and "product dimension of visual art curriculum". Furthermore, in order to test the validity of the two-factored structure identified through Exploratory Factor Analysis Confirmatory Factor Analysis was also calculated. According to the results of the confirmatory factor analysis (CFA) and when the fit index was considered Root Mean Square Error of Approximation ordinal value was 0.05 and therefore, below the accepted 0.08 value. The GFI value was 0.92 , above the accepted 0.90 value; and the calculated CFI value was found as 0.94 and therefore above the 0.90 . The NFI value was found as 0.91 and thus identified as above the accepted 0.90. When examining the Randall and friends fit index (2004), the findings of the analysis were statistically approved.

\section{Interview Form}

An interview form was prepared by the researchers of this study to identify the teachers' opinions on visual art curriculum. Before the interview form was prepared, the literature was reviewed and the current statuses of the curricula of the two communities were investigated. The interview form consisted of two dimensions. First, the demographic features of teachers were decided to include: gender, professional experience, education level, age ranges, nationalities, in-service training statuses, and participation in exhibition statuses. In the process of constructing the semi-structured interview questions, face-to-face meetings were held with 4 visual art teachers working in the two communities and their views and opinions were consulted. An item pool was constructed according to the literature review and meetings with the teachers and specialists were held. Moreover, a meeting was also held with 3 program development specialists working in the two communities, 4 art education specialists and 2 assessment and evaluation specialists and the necessary corrections were made. The interview form was designed as 4 items, and after the specialists were consulted, relatedness of the scope and field was re-checked and the 2 items which were found as unnecessary by the specialists were removed. As a result, 2 items were removed from the interview form based on their feedback. Content validity was achieved with 3 Greek Cypriot and 3 Turkish Cypriot visual art teachers through a pilot study and data analysis. The form to be used for the southern community was prepared in English and the form to be used in the northern community was prepared in Turkish. Furthermore, the English form to be administered in the south was prepared by 2 translators whose native language was Turkish and English. Also, the translation method used for the research was the traditional method (Rogers et al., 2016) and in the first stage, the Turkish expressions were translated into English to the targeted audience. Later, this translation was translated back into Turkish, and the validity of the two translations was checked. Moreover, a semantic unity of the translations was checked during this process and tested by 4 bi-lingual specialists who speak both Turkish and English.

\section{Data Analysis}

The qualitative data of the study was analysed by the researchers of the study through grouping the data via descriptive analysis. The interview questions were accepted as themes and sub-themes were constructed from the teachers' responses to these questions. On the other hand, the quantitative data was analysed in terms of percentages, mean, standard deviation, independent $t$-test and interpreted through 0.05 value.

\section{Preliminaries}

The first phase of the research involved a pilot study in Northern and Southern Nicosia schools. The questionnaire based on a scale was administered in selected 4 private secondary schools and delivered to 800 students and the findings were analysed accordingly. The other phase of the research continued in Northern Nicosia. Before the pilot of the scale was administered in Northern Cyprus, the necessary permissions were taken from the Ministry of Education in the North. Then, the principals of the schools which agreed to participate in the 
research were visited to arrange the research application date. The researchers went to the Turkish schools in Northern Nicosia at the agreed date and time. The students were informed regarding the scale and then the scale was administered.

The other phase of the research was collecting the opinions of visual art teachers. The interview forms first given to the teachers in Southern region. The Greek Cypriot teachers who participated in the face-to-face interviews showed a positive approach to the research and no problems have been encountered by the researchers during the research conducted in the Southern part of Cyprus. After the interviews in the Southern Nicosia were completed, the teachers in the Northern region of Cyprus were interviewed. The interviews were all completed within two months and without encountering any problems either in Northern or in Southern Nicosia.

\section{FINDINGS}

\section{Teachers' Opinions on Visual Art Curriculums Implemented in Year Eight, Secondary Education in Northern and Southern Cyprus}

As the purpose of this research was to identify the opinions of Greek and Turkish Cypriot teachers on visual art curricula used in year eight, secondary education, the opinions of teachers about the visual art curricula were examined, similarities and differences between the curricula used in the two communities were also identified and compared. The first theme created by analysing the qualitative data obtained from the research was the positive and negative aspects of visual art curricula. This theme was then sub-categorised within itself as: "Preparatory level of students", "Up-to-datedness of the curriculum", "Hand skills and power of expression" and "The effects of the program on students' identity and psychology". Referring to the necessity of bringing art education to the students at an early age, teachers stated that there was a deficiency in teaching programs since the consideration to include the students in the creation of teaching programs were not taken into account. Moreover, the participating teachers expressed their belief that the study held significance for both the communities on the island. For example, a Turkish Cypriot Teacher (TCT1): "Children's perceptions are weak, they are not aware of what is going on around them. For this reason, it is difficult for me to reach the basics of the course. Students' knowledge on art is low from primary schools. I believe that this course should be taught more sufficiently and entertaining way at the primary school level." On the other hand, a Greek Cypriot teacher (GCT9): "I find students' knowledge of art at primary school level insufficient, the topics are not up to date. Once the student moves to secondary education level with insufficient knowledge, the knowledge presented at secondary education is never permanent." Bringing a different perspective to the issue, the teachers have expressed the need for visual art curriculum content to be developed; making it contemporary and suitable for today's conditions. "I think that the topics are classic and based on memorization, which does not develop the students' knowledge. Art education curricula should be more creative, allowing room for original ideas, discovery and freer topics".

Greek Cypriot Teacher (GCT7) expresses a similar expression: “The visual art curriculum does not involve sufficient artistic skills. Rather, it includes a restrictive approach such as drawing what can be seen. In contrast, I believe that it should be freer and directed towards the learners. The curriculum should not be filled with pre-determined subjects and should be designed in a way that sets the students free". As can be seen, the qualitative data collected reveal similarities between the Turkish and Greek Cypriots regarding the negative aspects of the visual art curricula.

The positive aspects expressed by the year eight visual art teachers emphasised that the curricula implemented particularly included: "free expression", "creative skill", "aesthetic perception", "hand skill", "cultural learning and identity developing" features. For example, Greek Cypriot Teacher (GCT1) points out, "Students were provided with space to freely express themselves. We are following up on communal incidents and are including them in art projects". On the other hand, Turkish Cypriot Teacher (TCT4) expressed that: "The curriculum we administer provides the students with the opportunity to discover and display their talents. They can developing their imagination and concretely display these. They can establish empathy and respect humans. In other words, they take steps which make them humanists". Another teacher (GCT7), emphasised the positive effect of the curriculum as it made a contribution to develop identity: "In my view, the strongest aspect of the curriculum is that it enabled individuals to express themselves and most importantly, allowing the students to freely express themselves, and quip them with skills to communicate 


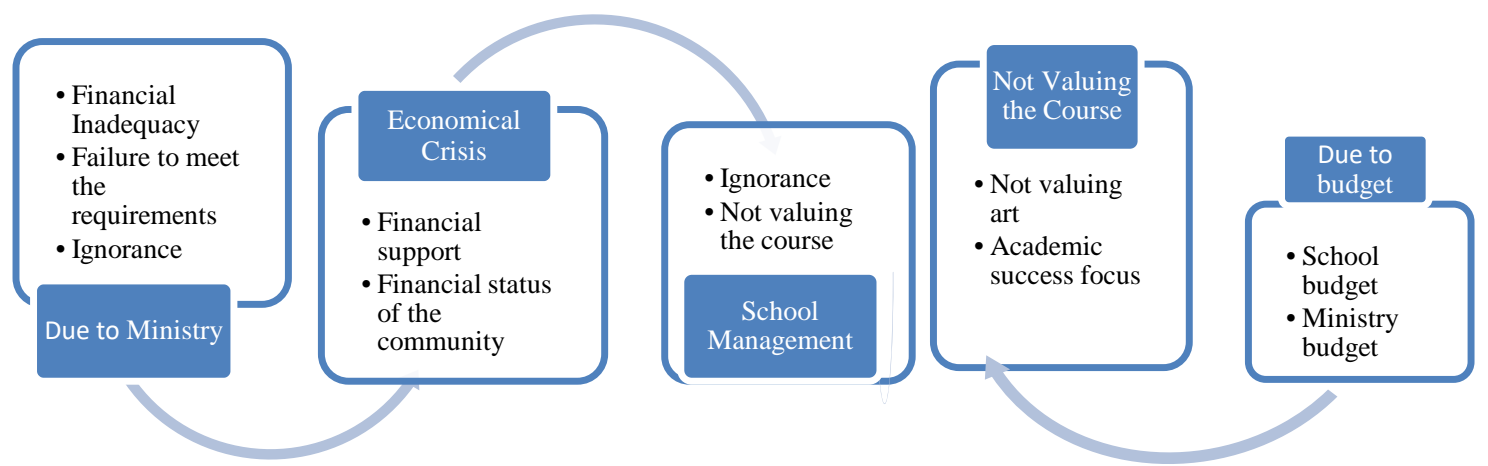

Figure 1. Teachers' opinion on the physical setting in which year eight visual arts curriculum

with others and also raising their awareness of reconciliatory identity." Moreover, Greek Cypriot Teacher (GCT11) said, "Unlike other courses, this course does not stress the students. Students are usually happy about drawing a picture and find the opportunity for a freer time. That is, during the intense courses of the daily program, students need courses such as music and art". Turkish Cypriot Teacher (TCT5) expressed, "Students are constantly preparing for examinations and are constantly encountering intense educational programs. For this reason, art lessons are very important as they create opportunities for students to discover themselves and spend freer times". In conclusion, it was observed that the data collected was on visual art curricula were positive.

\section{Northern and Southern Cyprus Teachers' Opinions Regarding the Physical Settings in which Year Eight Visual Art Curricula are Implemented}

This research also aimed to determine the opinions of teachers from Northern and Southern Cyprus regarding the physical settings in which Year Eight visual art curricula are implemented. That is, the opinions of teachers working in Northern Cyprus were identified regarding the physical settings in the north; whereas the opinions of teachers working in Southern Cyprus were identified on the physical settings available in the south. The data collected from both the communities were grouped under five main themes. The five themes are summarised in Figure 1.

As can be seen in Figure 1, the Turkish and Greek Cypriot Teachers' Opinions on the physical setting in which the year eight visual art curricula administered is grouped under five main themes. Furthermore, the teachers who provided their opinions also provided their views on ideal features of the physical setting necessary for this course. Additionally, the teachers expressed negative opinions on the current physical setting in which the curriculum is implemented. The sub-themes identified from the Turkish and Greek Cypriot Teachers' Opinions on the physical setting are as follows:

- Shortcomings caused by the Ministry

- Economical crisis

- Shortcomings due to school management

- Not valuing the course

- Shortcomings due to budget

Teachers from both communities have expressed that the eighth-year visual art courses are done in workshops which lack equipment. However, compared to the equipment that Turkish Cypriot teachers have in their workshops, the workshops which the Greek Cypriot teachers have been found to be better equipped. Furthermore, while some Greek Cypriot teachers expressed that their workshops lacked equipment, others have expressed that their equipment were adequate. On the other hand, once the views of Turkish Cypriot teachers were asked on the same issue, teachers have expressed agreement that the workshops were extremely inadequate in terms of equipment. In this regard, it is clear that compared to the schools in the South, the schools in the North have more inadequacy related to the physical settings in which the courses are done. The vast majority of the 
Turkish Cypriot teachers indicated that these shortcomings stemmed from the Ministry of Education. One of the Turkish Cypriot Teachers who participated in the research has expressed these shortcomings as follows: "The Ministry of Education does not show interest to our needs. We must have independent workshops, enough materials should be provided to the students, smart boards and technological goods must be available in the workshop environments. However, these needs are not being provided to us by the Ministry of Education" (TCT1).

Another Turkish Cypriot teacher expresses opinions on the matter as: "First of all, I need a projection to be able to project relevant visuals to the students in my class. The Projection device is only one of the things we need...Whenever I inform the Ministry of our needs; I am told that the budged is insufficient. In this regard, we as teachers are struggling and are trying to obtain our needs through our own initiatives. We have succeeded to get support from the EU and the TR Support Committee" (TCT10).

Furthermore, other Turkish Cypriot Teachers (TCT7 \& TCT10) have made similar statements: “I need equipment such as a smart board and a projection. While teaching great artists, I wish to support my teaching with visuals. However, I have not asked the Ministry of Education to provide my needs as I know that they prioritise other lessons. Furthermore, the Ministry of Education is displaying an approach fully focused on academic success. Most probably, they will not consider the needs of visual art lessons".

Therefore, the teachers have expressed that the physical settings in which visual art lessons are conducted are insufficient in terms of equipment. Moreover, differently, from other teachers, TCT7 emphasised belief that the Ministry of Education focused on academic success; stressing that the visual art lessons were pushed towards the end of the line in terms of importance. On the other hand, TCT6 expressed; "Currently, the workshop is in a good state since it is supported by the Parent-School Association and School Management. However, I have to bring my own things to provide the students' needs. I want to provide our needs to the inspector in charge at the Ministry of Education. Each year, I inform them regarding our needs by making a list but nothing happens resultantly. I believe that the visual art lessons are not taken seriously at all. We have achieved everything with our own efforts. There is a need to support the students who do not have good economical statuses, and this needs to be done by the Ministry", which means that the needs of the visual art workshops were provided by school management and the school-parent association, therefore provided with their own means.

Therefore, it is apparent that all of the Turkish Cypriot teachers are complaining regarding the inadequacy of the physical settings in which visual art lessons are conducted in. On the other hand, when the Greek Cypriot teachers' opinions were examined on the matter, some teachers have expressed their belief that the inadequacy of the workshops was due to the economic crisis that their country was in. One of these teachers has expressed this belief as follows: "the workshop which I teach in is insufficient; I need more materials and fixture. However, due to the economic crisis, the Ministry of Education is encountering difficulties in providing these. Sculpture, ceramics and better-quality paint are among my most important needs" (GCT3).

Similarly, GCT8 expressed a need for many materials: "In the past, we had a bigger budged, however, this year we are on a more restricted budget due to the economic crisis. I want to get projects done with different materials. For example, I need materials to make ceramic, mud and metal work.

On the contrary, some Greek Cypriot teachers have expressed that the physical setting in which they did their visual art lessons were adequate. One teacher expressed this opinion as: "I am pleased with my workshop. Every year, we are provided materials and paints from the budget" (GCT4).

Expressing that they were supported by the Ministry of Education, GCT9 has expressed similar thoughts as: "The physical setting that we are in is suitable for drawing. We are benefitting from the budget which the Ministry provides for us to obtain the materials and other needs, each year. Therefore, I am not encountering any serious problems. We are using recyclable material to make different projects".

To sum up, while the Turkish Cypriot teachers all agree that the physical setting in which visual art lessons are conducted had many inadequacies, it was observed that the Greek Cypriot teachers' opinions on the matter varied. Some Greek Cypriot teachers argued that the workshops were inadequate; others have said that the 
Table 1. Score distribution of Turkish and Greek Cypriot students' opinions on visual art curriculums

\begin{tabular}{ccccccc}
\hline Nationality & Dimension & $\mathbf{N}$ & Minimum & Maximum & Mean & SD \\
\hline \multirow{2}{*}{$\begin{array}{c}\text { Turkish } \\
\text { Cypriot }\end{array}$} & Process & 600 & 1.00 & 5.00 & 3.28 & .872 \\
\cline { 2 - 7 } & Product & 600 & 1.00 & 5.00 & 2.96 & .764 \\
\cline { 2 - 7 } & Total & 600 & 1.00 & 5.00 & 3.17 & .793 \\
\hline \multirow{2}{*}{$\begin{array}{c}\text { Greek } \\
\text { Cypriot }\end{array}$} & Process & 600 & 1.00 & 5.00 & 3.48 & .840 \\
\cline { 2 - 7 } & Product & 600 & 1.00 & 5.00 & 3.37 & .790 \\
\cline { 2 - 7 } & Total & 600 & 1.00 & 5.00 & 3.44 & .784 \\
\hline
\end{tabular}

workshops were sufficiently equipped. The difference between the opinions of the Greek Cypriot teachers is believed to be due to the socio-economic statuses of the schools in which these teachers are working in.

\section{Students' Opinions Regarding the Visual Art Curriculums Implemented in Year Eight, Secondary Education in Northern and Southern Cyprus}

This research aimed to identify the year eight students' opinions on the visual art curriculums implemented in secondary education in Northern and Southern Cyprus. The opinions of Turkish Cypriot students studying in Northern Cyprus were examined in the year eight visual art curriculums implemented in Northern Cyprus. On the other hand, the opinions of Greek Cypriot students studying in Southern Cyprus were examined in the year eight visual art curriculums implemented in Southern Cyprus. The students' opinions gathered through the "Visual Art Curriculum Evaluation Scale" are provided in Table 1.

As can be seen in Table 1, the Turkish Cypriot students' opinions on the process dimension of year eight visual art curriculum are within the "Indecisive" range $(\mathrm{M}=3.28, \mathrm{Sd}=.872)$. The Greek Cypriot students' opinions are within the "I agree" range $(\mathrm{M}=3.48, \mathrm{Sd}=.840)$. The findings of the research reveal that the Greek Cypriot students' opinions on the process dimension of the curriculum implemented in Southern Cyprus are more positive than those of the Turkish Cypriots. In contrast, it has been determined that both the Turkish $(\mathrm{M}=2.96, \mathrm{Sd}=.764)$ and the Greek $(M=3.37, S d=.790)$ students' opinions on the product dimension of the visual art curricula was not positive enough. Furthermore, as represented in Table 1, the students in both the communities were abstaining on the product dimension of the curricula. Therefore, the re-evaluation of the product dimension of the visual art curricula is seen as a necessity.

The total score distribution of Year Eight Turkish Cypriot students who provided their opinions on visual art curricula is $(\mathrm{M}=3.17, \mathrm{Sd}=0.793)$; whereas the score distribution of the Greek Cypriot students has been calculated as $(M=3.44, S d=0.784)$. The findings of the research indicate that the Greek Cypriot students' opinions on the visual art curriculum implemented in Southern Cyprus are more positive than the Turkish Cypriot students' opinions on the visual art curriculum implemented in Northern Cyprus. Such that the Turkish Cypriot students' opinions on visual art curriculum are within the "indecisive" range; whereas the Greek Cypriot students' opinions on the visual art curriculum implemented in Southern Cyprus are identified to be within the "I agree" range. The fact that the Turkish Cypriot students' opinions on the visual art curriculum implemented in Northern Cyprus are generally "indecisive" indicates that they are in an abstaining attitude towards the program.

Similarly, it was found that the Greek Cypriot teachers' opinions on the visual art curriculums and the physical setting the program is implemented in are more positive than the opinions of the Turkish Cypriot teachers (See 3.1 and 3.2). Therefore, it is possible to conclude that the year eight visual art curriculum implemented in Southern Cyprus comprises more positive features than the one implemented in Northern Cyprus.

While evaluating the year eight visual art curricula, developed independently from each other and implemented in Northern and Southern Cyprus, the Turkish and Greek Cypriot students have provided expressions which indicate that they are of the same mind regarding the positive aspects and the deficiencies of the curriculum. For example, to the "I learn topics related to our culture" expression both the Turkish Cypriot students 
Table 2. A comparison of taking private visual art lesson of year eight students studying in Northern and Southern Cyprus

\begin{tabular}{|c|c|c|c|c|c|c|c|c|}
\hline Nationality & Dimension & Status on taking private lessons & $\mathbf{N}$ & Mean & SD & df & $\mathbf{T}$ & $\mathbf{P}$ \\
\hline \multirow{4}{*}{$\begin{array}{l}\text { Turkish } \\
\text { Cypriot }\end{array}$} & \multirow{2}{*}{ Process } & Yes & 29 & 3.10 & .999 & 598 & 1.540 & .124 \\
\hline & & No & 566 & 2.87 & .752 & & & \\
\hline & \multirow{2}{*}{ Product } & Yes & 29 & 3.49 & .956 & 598 & 1.223 & .222 \\
\hline & & No & 566 & 3.29 & .867 & & & \\
\hline \multirow{4}{*}{$\begin{array}{l}\text { Greek } \\
\text { Cypriot }\end{array}$} & \multirow{2}{*}{ Process } & Yes & 203 & 3.60 & .766 & 598 & 5.894 & .000 \\
\hline & & No & 397 & 3.21 & .785 & & & \\
\hline & \multirow{2}{*}{ Product } & Yes & 203 & 3.80 & .739 & 598 & 6.652 & .000 \\
\hline & & No & 397 & 3.34 & .841 & & & \\
\hline
\end{tabular}

$(M=3.49, S d=1.174)$ and the Greek Cypriot students $(M=3.55, S d=1.18)$ have stated opinions within the range of "I agree". From the findings, it is clear that the curricula used in both the communities value 'cultural values'.

Furthermore, both the Turkish Cypriots (M=3.42, Sd=1.31) and the Greek Cypriots (M=3.57, Sd=1.25) have responded positively to "The drawing topics encourage me to create original ideas". Moreover, on the "My imagination improved" expression, both the Turkish Cypriot students $(M=3.62, \mathrm{Sd}=1.30)$ and the Greek Cypriot students $(\mathrm{M}=3.66, \mathrm{Sd}=1.20)$ responded positively. It was determined that the Greek Cypriot and Turkish Cypriot students provided similar responses related to the deficiencies of the curriculum through their responses to "We read art books" and "My teacher takes us to out-of-school exhibitions". Such that, to the "We read art books" expression, Turkish Cypriot students $(\mathrm{M}=2.42, \mathrm{Sd}=1.27)$ responded as "I do not agree" and the Greek Cypriot students $(M=2.91, \mathrm{Sd}=1.32)$ responded as "I am indecisive". The findings of the research show that both the Turkish and the Greek Cypriot students negatively responded to "We read art books".

Additionally, the Turkish Cypriot students responded to "Our teacher takes us to out of school exhibitions" as "I do not agree" (M=2.03, $\mathrm{Sd}=1.27)$; whereas the Greek Cypriot students responded as "I am indecisive" (M=2.87, $\mathrm{Sd}=1.40)$. Moreover, the research findings reveal that most of the events related to visual art in both the Greek Cypriot and the Turkish Cypriot communities take place in the school settings and are related mostly to theoretical knowledge.

\section{Findings Related to Year Eight Visual Art Students' Statuses on Taking Private Visual Art Lessons in Northern and Southern Cyprus}

This research also included a focus on determining whether taking private visual art lessons made a strong impact on the year eight visual art students' opinions regarding the visual art curricula implemented in Northern and Southern Cyprus. For this purpose, independent sample t-test analysis was used to the data collected. Table 2 shows the score distribution related to Turkish and Greek Cypriot students' status of taking private visual art lessons.

As indicated in Table 2, a significant difference between the opinions of Turkish Cypriot students who take private visual art lessons $(\mathrm{M}=3.10, \mathrm{Sd}=.999)$ and opinions of students who do not take private lessons $(\mathrm{M}=2.87$, $\mathrm{Sd}=.752$ ) has not been identified in terms of the process dimension of the visual art curriculum. Similarly, there was no significant difference in the opinions of the Turkish Cypriot students $(M=3.49, S d=.956)$ who take private visual art lessons and students who do not take a private lesson in terms of product dimension of the visual art curriculum. Therefore, the findings of the research reveal that taking private visual art lessons does not make a significant difference in the Turkish Cypriot students' opinions on the year eight visual art curriculum.

On the other hand, when examining the difference between the Greek Cypriot students taking private visual art lessons $(\mathrm{M}=3.60, \mathrm{Sd}=.766)$ and the Greek Cypriot students who do not take private lessons $(\mathrm{M}=3.21$, $\mathrm{Sd}=.785)$, a significant difference was identified regarding the students' opinions on the process dimension of the year eight visual art curriculum $(t=5.894, p<0.05)$. Similarly, when examining the average points of Greek Cypriot 
students who take private visual lessons $(\mathrm{M}=3.80, \mathrm{Sd}=.739)$ and the average points of those who do not take private lessons $(\mathrm{M}=3.34, \mathrm{Sd}=.841)$, a significant difference was identified regarding the opinions of students on the product dimension of the year eight visual art curriculum $(t=6.652, \mathrm{p}<0.05)$.

As indicated in Table 2, in terms of the product dimension of the year eight visual art curriculum, the opinions of Greek Cypriot students who take private visual art lessons are more positive than the Greek Cypriot students who do not take private lessons. The students who consciously take private visual art lessons outside the school clearly show a higher interest and desire for the field than the students who do not take private lessons. This can also be interpreted as the opinions of students who take private lessons are positively influenced in terms of their opinions on visual art curriculum, compared to the students who do not take private lessons. Another finding identified in the research is that the number of Turkish Cypriot students who take private visual art lesson is extremely lower than the number of Greek Cypriot students who take private lessons. As shown in Table 2, from the participating year eight students only 29 Turkish Cypriot students take private visual art lessons whereas 203 Greek Cypriot students take private lessons. In this regard, it is believed that the Greek Cypriot students' interest in art is higher than the interest of Turkish Cypriot students. Furthermore, it is believed that the Greek Cypriot students take private lessons since they want to increase their knowledge on visual art lessons.

\section{DISCUSSION AND CONCLUSION}

Once examining the opinions of teachers who implement year eight visual art curriculum, it was found that teachers in both communities had similar views regarding the positive features of the visual art program. In this regard, both the Greek and the Turkish Cypriot teachers expressed a common belief that the visual art lessons developed positive personality traits in students. Moreover, the teachers have also expressed that the visual art lessons had an effect on nurturing sensitivity in individuals toward communal events, establishing personality traits such as empathy and humanism. The findings from similar research support the findings of this research (Chin 2016). Similarly, both Turkish Cypriot and Greek Cypriot teachers argued that the visual art curricula had a positive effect on student psychology. In his research, Vanada (2016), emphasised that visual art lessons had a positive impact on students in terms of their perception and skills, which in turn, acts like a therapy on the students. Furthermore, in their research Navenen et al. (2014), point out that the visual art lessons made positive contributions to individuals such as; overcoming daily issues, gaining aesthetic and ethical values, creating opportunities to express one's self, and develop social skills. In this regard, it is clear that the findings of the literature support the findings of this particular study.

The Greek and Turkish Cypriot teachers who provided their opinions to the research not only pointed out the positive features of the year eight visual art curricula but also pointed out its deficiencies. They stated that the year eight visual art curricula were prepared without taking the readiness levels of students into account and added that this caused them to encounter difficulties while teaching the topics of the lesson. In the research carried out by Mamur (2015), states that the students who had learnt the past topics well were ready to learn the next topic and therefore, had higher levels of success. Thus, the necessity to consider students' readiness levels in the year eight visual art curriculums in Northern and Southern Cyprus is rather significant.

Another issue, which the visual art teachers agree as for shortcoming of the program, is that the content of the visual art curriculum did not go beyond the classical art education. In their study, Leonard and Odutola (2016), draw attention to the need to take students' needs into account and emphasise that the content of the visual art curricula needed to be updated. This research has also revealed that the physical settings in which the Year Eight visual art curricula are implemented in were differing in some respects. The findings related to this issue indicate that the Turkish Cypriot teachers emphasised that the physical environment in which they implement the curriculum was insufficient. On the contrary, an agreement between the Greek Cypriot teachers on the same issue has not been found and their views were found to be varying. While some Greek Cypriot teachers expressed that they implemented the visual art curriculum in an insufficient physical environment; others have expressed that the physical setting in which they implemented the curriculum was fairly sufficient. The Greek Cypriot teachers who had expressed that the physical setting they worked in was sufficient also emphasised that the Ministry of 
Education in Southern Cyprus provided the necessary support in this direction. However, once examining the Turkish Cypriot teachers' opinions it was found out that the teachers emphasised the lack of support for the physical setting of visual art lessons from the Ministry of Education in Northern Cyprus. In their research, Atan and Dalkıran (2008), state that the physical setting in which the visual art lessons are conducted play an important role in increasing the teacher and student interactivity. Therefore, it is strongly believed that there is a need to emphasise the importance of physical environments in which the visual art curricula are implemented in Northern Cyprus.

In addition to the above, findings related to opinions of students on the Year Eight visual art curricula were also included in this research show that the views of Greek Cypriot students regarding the program were more positive compared to the views of the Turkish Cypriot students. In this regard, it was found out that both the Turkish Cypriot teacher and students were in a more negative and abstentious mood in comparison to the views of the Greek Cypriot teachers and students. Additionally, the fact that the teachers' and students' opinions show similarities indicates that the research findings are consistent within themselves.

The research also involved examining the statues of students regarding taking private visual art lessons and to evaluate if this status made an influence on their opinions on the visual art curriculum. The findings related to this investigation reveal that Turkish Cypriot students' statuses of taking private lessons did not create a difference on their views regarding the visual art program. However, once considering the Greek Cypriot students, it was found out that their statuses of taking private visual art lessons influenced their opinions on visual art program. In this regard, it can be stated that the students who take private lessons have higher awareness of the visual art program. Moreover, it was found that the number of Greek Cypriot students who take private lessons is higher than the number of Turkish Cypriot students. The fact that not a high number of Turkish Cypriot students take private visual art lessons is believed to be due to financial statuses of their families. In their research, Upitis (2011), point out that students with families of high income participate to out-of-school art activities more than the students who have families with lower income. Therefore, it is clear that the socio-economic status of families is a significant variable in art education.

\section{REFERENCES}

Altbach, P. (2015). Knowledge and education as international commodities. International higher education, (28). http://www.heart-resources.org/wp-content/uploads/2015/10/Knowledge-and-Education-asInternational-Commodities.pdf

Arkün, S., \& Aşkar, P. (2010). Yapılandırmacı öğrenme ortamlarını değerlendirme ölçeğinin geliştirilmesi. Hacettepe Üniversitesi Eğitim Fakültesi Dergisi, 39(39).

Atan, U., \& Dalkıran, A. (2008). İlköğretim Okullarındaki Görsel Sanatlar Dersi Öğretmenleri ve Fiziki Altyapı Standartlarına Yönelik Bir Durum Değerlendirmesi/A Study Into the Evaluation Of Conditions Related with Physical Infrastructure Standards And Visual Arts Teachers in Primary Sch. Mustafa Kemal Üniversitesi Sosyal Bilimler $\quad$ Enstitüsü http://sbed.mku.edu.tr/article/view/1038000499/1038000291

Bamford, A. (2006). The wow factor: Global research compendium on the impact of the arts in education. WaxmannVerlag. https://books.google.com.cy/books/about/The_Wow_Factor.html?id=ZEaxmwG9n4EC\&redir_esc=ya

Chin, C. (2016). Moving Beyond a Human Relations Approach in Multicultural Art Education Practice. International Journal of Education \& the Arts, 17(4). http:/ / www.ijea.org/v17n4

Cremin, T. (2016). Introduction-Creativity and creative pedagogies: Exploring challenges, possibilities and potential (pp. xvii-xxvii). Routledge. http://oro.open.ac.uk/id/eprint/46486

Dewey, P. (2008). A comparative approach to art education policy research. Studies in art education, 49(4), 277-293. doi:10.1080/00393541.2008.11518742

Gökel, Ö., \& Dağlı, G. (2015). Osmanli'dan günümüze Kıbrıs Türk eğitim sisteminin geçirmiş olduğu evreler. Journal of International Social Research, 8(37). 
Hung, W. T. B., \& Smith, J. (2015). Visual culture and art making in tertiary art schools: A 'snapshot'from Hong Kong and New Zealand. http://www.ied.edu.hk/cca/apjae/Vol14_No2.pdf

Jeong, O. H. (2017). An Autoethnographical Study of Culture, Power, Identity and Art Education in Post-Colonial South Korea. International Journal of Art \& Design Education, 36(1), 9-20.

Kambouri, M. (2012). The educational system in Cyprus. Proceedings of WIEGA, 5, 57-67. https://www.academia.edu/2436641/ THE_EDUCATIONAL_SYSTEM_IN_CYPRUS

Karpati, A., Freedman, K., Castro, J. C., Kallio-Tavin, M., \& Heijnen, E. (2017). Collaboration in Visual Culture Learning Communities: Towards a Synergy of Individual and Collective Creative Practice. International Journal of Art E Design Education, 36(2), 164-175. doi:10.1111/jade.12099

Kızılyürek, N. (2016). Okullarımızda Kıbrısılı Rum Edebiyatçıları Ne Zaman Göreceğiz. United Media Group, December 11. http://www.yeniduzen.com/okullarimizda-kibrisli-rum-edebiyatcilari-ne-zamangorecegiz-9552yy.htm

Kraehe, A. M., Acuff, J. B., Slivka, K., \& Pfeiler-Wunder, A. (2015). Conversations extended: Art education in context. Art Education, 68(6), 6-8. doi:10.1080/000431252015.11519341

Kroflic, R. (2007). How to Domesticate Otherness: Three Metaphors of Otherness in the European Cultural Tradition. Philosophical Inquiry in $\quad$ Education, 16(3), 33. http://journals.sfu.ca/pie/index.php/pie/article/view/133.

Leeman, Y. (2017). Whither cultural diversity and intercultural education in the Netherlands? In Global Teaching (pp. 17-33). Palgrave Macmillan US. doi:10.1080/03057920500382325

Leigh, B. R. (2004). Civics and Citizenship Education: Historical and Comparative Reflections. Journal Civics: Media KajianKewarganegaraan. doi:civics.v1i1.5662

Leonard, A. E., \& Odutola, A. O. (2016). "I Am Artistic": Mixed Method Case Study Research of Preservice Generalists' Perceptions of Arts in Education. Studies in Art Education,57(3), 279-299. doi:10.1080/00393541.2016.1178019

MacMullen, I. (2015). Civics beyond critics: Character Education in a liberal democracy. OUP Oxford. doi:10.1177/1478929916673771

Mamur, N. (2015). Critical Pedagogical Approaches to Visual Culture in Turkish Preservice Education. Studies in Art Education, 56(4), 355-368. doi:10.1080/00393541.2015.11518976

Matthews, K. E., Belward, S., Coady, C., Rylands, L., \& Simbag, V. (2016). Curriculum development for quantitative skills in degree programs: a cross-institutional study situated in the life sciences. Higher Education Research E Development, 35(3), 545-559. doi:0.1080/07294360.2015.1107875

Nevanen, S. (2015). Focusing on arts education from the perspectives of learning, wellbeing, environment and multiprofessional collaboration: Evaluation research of an arts education project in early childhood education centres and schools. http:/ / urn.fi/URN:ISBN:978-951-51-1124-1

O'Sullivan, M. C. (2006). Teaching large classes: The international evidence and a discussion of some good practice in Ugandan primary schools. International Journal of Educational Development,26(1), $24-37$. doi:10.1016/j.ijedudev.2005.05.010

Papadakis, Y. (2008). Narrative, Memory and History Education in Divided Cyprus: A Comparison of Schoolbooks on the "History of Cyprus". History \& Memory, 20(2), 128-148. https://muse.jhu.edu/article/246800/summary

Phillips, D. (2015). Policy borrowing in education: Frameworks for analysis. In Second international handbook on globalisation, education and policy research (pp. 137-148). Springer Netherlands. doi:10.1007/978-94-017-94930_9

Rogers, K. D., Pilling, M., Davies, L., Belk, R., Nassimi-Green, C., \& Young, A. (2016). Translation, validity and reliability of the British Sign Language (BSL) version of the EQ-5D-5L. Quality of Life Research, 25(7), 18251834.

Savery, J. R. (2015). Overview of problem-based learning: Definitions and distinctions. Essential readings in problembased learning: Exploring and extending the legacy of Howard S. Barrows, 9, 5-15. 
Thomas, D., \& Brown, J. S. (2011). A new culture of learning: Cultivating the imagination for a world of constant change (Vol. 219). Lexington, KY: Create http://www.journalofplay.org/sites/www.journalofplay.org/files/pdf-articles/4-1-book-review-1.pdf

Turner, D. A. (2017). Comparison as an approach to the experimental method. Compare: A Journal of Comparative and International Education, 47(3), 406-415. doi:10.1080/03057925.2016.1243041

Upitis, R. (2011). Arts education for the development of the whole child. Elementary Teachers' Federation of Ontario.

Vanada, D. I. (2016). An Equitable Balance: Designing Quality Thinking Systems in Art Education. International Journal of Education $\mathcal{E}$ the Arts, 17(11). http://www.ijea.org/v17n11/

Winkler, H., \& Denmead, T. (2016). The Future of Homegrown Teaching Artists? Negotiating Contradictions of Professionalization in the Youth Arts and Humanities Fields. International Journal of Education $\mathcal{E}$ the Arts, 17(10). http://www.ijea.org/v17n10/

Zembylas, M. (2002). The global, the local, and the science curriculum: a struggle for balance in Cyprus. International Journal of Science Education, 24(5), 499-519.

Zembylas, M., Bekerman, Z., Haj-Yahia, M. M., \& Schaade, N. (2010). The politics of mourning in Cyprus and Israel: Educational implications. Compare, 40(5), 561-574. doi:10.1080/03057920902913917

Zembylas, M., Charalambous, C., \& Charalambous, P. (2016). Peace education in a conflict-affected society. Cambridge University Press. https:// books.google.com.cy/books?hl=en\&lr=\&id=Bi7xCwAAQBAJ\&oi=fnd\&pg=PR9\&dq=+Zembyla $\mathrm{s}$,+Michalinos, +Constadina + Charalambous, + and +Panayiota + Charalambous. + Peace+education $+\mathrm{in}+\mathrm{a}+\mathrm{co}$ nflict

\section{http://www.ejmste.com}

